\title{
A participação na construção do currículo: práticas educativas vinculadas ao movimento CTS
}

\section{Participation in curriculum construction: educational practices linked to the Science-Technology-Society movement}

\author{
Caetano Castro Roso ${ }^{1}$. Décio Auler ${ }^{2}$
}

\begin{abstract}
Resumo: Apresentamos uma análise sobre processos de definição e construção de currículos fundamentados em repercussões educacionais do movimento Ciência-Tecnologia-Sociedade (CTS). A pesquisa buscou responder como tem sido a definição e estruturação de currículos em práticas educativas realizadas no campo CTS. Analisamos artigos publicados em revistas brasileiras de Educação em Ciências focalizando práticas educativas efetivadas nesse campo. Utilizamos a Análise Textual Discursiva (ATD) na análise desses artigos. Enquanto referencial, esse esteve constituído de repercussões educacionais de CTS, pressupostos de Paulo Freire e proposições do Pensamento Latino-Americano em CiênciaTecnologia-Sociedade (PLACTS). Os resultados foram sintetizados em quatro categorias: (i) Currículos Temáticos, (ii) Professores selecionam temas para cumprir listagens de conteúdos, (iii) Não realização da investigação dos temas, e (iv) Focos de colaboração e interdisciplinaridade. Vinculado a essas categorias, identificamos limitações, dentre as quais destacamos: possível esvaziamento de pressupostos freireanos, indícios de um reducionismo metodológico e o consumismo não problematizado.
\end{abstract}

Palavras-chave: Movimento CTS. Educação em ciências. Currículo. Paulo Freire. Pensamento LatinoAmericano em Ciência-Tecnologia-Sociedade.

\begin{abstract}
We present an analysis about processes of definition and construction of curricula based on educational repercussions of the Science-Technology-Society (STS) movement. The study sought to respond the question: how has the definition and organization of curriculum been conducted in educational practices realized in the field of the STS movement? We analyze articles published in Brazilian journals concerning education in sciences, focused on educational practices in this field and use Discursive Textual Analysis (DTA). The references included the educational repercussions of STS, concepts of Paulo Freire and proposals of the Latin American Thinking in Science-Technology-Society (LATSTS). The results were summarized in: (i) Thematic Curriculum, (ii) Teachers Selection of Themes to Comply Lists of Contents, (iii) the Non-Realization of the Investigation of the Themes and (iv) Foci of the Collaboration and Interdisciplinarity. We identify limits that indicate challenges to science education: possible weakening of Freire's concepts, indications of a methodological reductionism and the non-problematized consumerism.
\end{abstract}

Keywords: STS Movement. Science education. Curriculum. Paulo Freire. Latin American Thinking in Science-Technology-Society.

\footnotetext{
${ }^{1}$ Universidade Federal de Santa Catarina (UFSC), Programa de Pós-Graduação em Educação Científica e Tecnológica, Florianópolis, SC, Brasil. E-mail: <caetanoroso@gmail.com>.

${ }^{2}$ Universidade Federal de Santa Maria (UFSM), Programa de Pós-Graduação em Educação, Santa Maria, RS, Brasil.
} 


\section{Encaminhamento teórico-metodológico}

Repercussões educacionais do movimento Ciência-Tecnologia-Sociedade (CTS) têm se disseminado e, cada vez mais, estão presentes na Educação em Ciências no Brasil, seja na Educação Básica, Superior e na pesquisa em Educação em Ciências. Essa disseminação tem sido bastante polissêmica. Entendemos que isso decorre, dentre outros aspectos, das distintas perspectivas educacionais associadas, das diferentes concepções de sociedade, de ciência e de tecnologia, bem como de suas relações, assumidas pelos que trabalham nesse campo. Pesquisas vêm sendo conduzidas no sentido de melhor caracterizar repercussões educacionais de CTS, no contexto brasileiro, aspecto que corrobora a consolidação da linha de pesquisa, no país, em termos de tendências, fundamentos teórico-metodológicos e sinalizações, conforme já identificaram autores como Delizoicov (2007), Lengruber (2000), Roso (2014), Roso, Dalmolin e Auler (2011) e Strieder (2012). Tais pesquisas têm sinalizado a grande diversidade de encaminhamentos associados a CTS, bem como a necessidade de uma maior definição conceitual (ROSO, 2014).

A gênese do movimento CTS está associada, dentre outros aspectos, à problematização do modelo tradicional/linear de progresso, à problematização da suposta neutralidade da Ciência-Tecnologia (CT), à preocupação com a degradação ambiental, assim como à busca de uma cultura de participação em processos decisórios envolvendo CT (GARCÍA; CEREZO; LÓPEZ, 1996). Esse movimento social mais amplo repercutiu, no âmbito educacional, em termos de objetivos e mudanças no campo curricular. No conjunto de manifestações relacionadas a CTS, ocorridas no Hemisfério Norte, estava a postulação por alguma forma de controle social sobre CT, sobre o direcionamento dado ao desenvolvimento científico-tecnológico, tornando-se um de seus objetivos centrais. Em outras palavras, a defesa de processos decisórios mais democráticos em detrimento de modelos tecnocráticos de tomada de decisões.

Já, na América Latina, principalmente na Argentina, entre os anos 1960 e 1970, um conjunto de professores universitários, pesquisadores nas áreas de ciências naturais, mobilizaram-se em direção ao que chamaram de um "projeto nacional" que colocava novos desafios relativos a CT (DAGNINO, 2008). Na época, em função do cenário econômico e produtivo, a região latino-americana vivenciava uma intensa transferência de tecnologias oriundas de países centrais. No entendimento desses pesquisadores, a CT desenvolvida nesses países não necessariamente seria adequada aos interesses e necessidades da população latino-americana, sendo, para eles, necessária uma reorientação da agenda de pesquisa em CT, de tal forma que essa incorporasse demandas e valores locais. Assim, nascia o que posteriormente foi denominado Pensamento Latino-Americano em Ciência-Tecnologia-Sociedade (PLACTS), que problematizava valores e objetivos da atividade científico-tecnológica (HERRERA, 2000a; VARSAVSKY, 1969), tendo como horizonte uma reorientação da atividade científico-tecnológica, buscando atender necessidades e demandas locais (SÁBATO; BOTANA, 1970; SÁBATO; MACKENZIE, 1982; VARSAVSKY, 1976). Em linhas gerais, o PLACTS tem sido ignorado na literatura do Hemisfério Norte.

Diferentemente do que ocorreu com referenciais de CTS do Hemisfério Norte, o PLACTS não repercutiu no campo educacional. Essa é uma construção que vem sendo trabalhada, atualmente, principalmente no Brasil, por alguns grupos de pesquisa ligados à Educação em 
Ciências ${ }^{3}$, aspecto que abordaremos posteriormente. Construção em curso e que problematiza o fato de que, em linhas gerais, práticas educativas balizadas por CTS, desenvolvidas no contexto latino-americano, pautam-se pelos pressupostos CTS do Hemisfério Norte. Ou seja, boa parte da repercussão educacional CTS, no Brasil, é importada, seja em termos de objetivos, conceituações e/ou visões de ciência, de tecnologia e de sociedade e, principalmente, das inter-relações entre CTS. Assim, por exemplo, o conceito de participação carrega marcas do espaço-tempo em que ocorreu sua gênese. Espaço-tempo esse com especificidades, demandas, características e interesses não necessariamente coincidentes aos da América Latina.

No Brasil, considerando a caminhada histórica, a transposição de pressupostos do PLACTS, para o campo educacional, é precedida por uma aproximação crítica entre pressupostos CTS, do Hemisfério Norte, e o pensamento educacional do educador brasileiro Paulo Freire (2005, 2006). Nesse sentido, destacamos os trabalhos de Auler (2002, 2007), Auler e Delizoicov (2006), Nascimento e Von Linsingen (2006), Roso, Dalmolin e Auler (2011), Santos (2008), Strieder (2008). Auler (2007), por exemplo, mesmo destacando a polissemia presente nesse campo CTS, destaca que há, entre esses encaminhamentos, alguns com dimensões que podem ser concebidas como complementares e articuláveis ao pensamento de Freire. Destaca três dessas dimensões em que considera a aproximação pertinente: a busca de currículos temáticos, a interdisciplinaridade e a construção de uma cultura de participação em processos decisórios.

Contudo, para um conjunto de autores, com o aprofundamento das pesquisas, foi ganhando corpo a compreensão da necessidade de aprofundar o conceito de participação, assim como um maior enraizamento latino-americano. Conceito de participação, conforme já destacamos, constituído no Hemisfério Norte. Assim, um novo conjunto de pesquisas (AULER, 2011; MONTEIRO, 2011; ROSA, 2014; ROSO, 2014; STRIEDER, 2012) passa a focalizar essa dimensão. Enquanto movimento social mais amplo, o CTS, com gênese no Hemisfério Norte, continha a preocupação com o redirecionamento do desenvolvimento científico-tecnológico, com a agenda de pesquisa. Preocupação que, segundo essas pesquisas, fica fragilizada, senão abandonada, quando repercute, no campo educacional, tanto no Hemisfério Norte quanto no Brasil.

Esse conjunto de pesquisas passa a identificar e problematizar o alcance limitado da participação social postulada. Uma participação que, em linhas gerais, limita-se ao "pós", pósdefinição da agenda de pesquisa, pós-execução de projetos. Uma linguagem usual desse tipo de participação consiste em: avaliar impactos positivos e negativos da CT, na sociedade, potencializando os primeiros e atenuando os segundos e discutir implicações de CT na sociedade. Ainda, uma participação pós-consumo, cabendo à educação buscar alternativas para atenuar o lixo produzido. Em geral, a reciclagem de lixo.

Assim, a problematização dessa concepção limitada de participação e a busca de horizontes ampliados de participação tem encontrado respaldo no PLACTS. Também presente no conjunto dessas pesquisas está a compreensão de que, para potencializar uma participação ampliada, no campo científico-tecnológico, mediante processos educativos, há que ampliar a participação na constituição dos currículos desses processos.

\footnotetext{
${ }^{3}$ Por exemplo, trabalhos vinculados ao Grupo de Estudos Temáticos em Ciência-Tecnologia-Sociedade (GETCTS), da UFSM, o grupo de Educação Científica, Cidadania e Mediação Pedagógica da UnB e o grupo Ciência, Tecnologia, Sociedade e Ambiente da UNIRIO.
} 
Nessa caminhada, nessa busca, situamos o problema de pesquisa que guiou a investigação cujos resultados estamos apresentando neste artigo. Ou seja, como tem sido a definição e estruturação de currículos em práticas educativas realizadas no campo CTS? Nesta pesquisa, assumimos como objetivos: (i) identificar quais sujeitos têm participado na definição de currículos de orientação CTS (ii); analisar encaminhamentos dados, relativamente ao campo curricular, em práticas educativas CTS; (iii) sinalizar horizontes para a Educação em Ciências na perspectiva de configurações curriculares pautadas pela constituição de uma cultura de participação.

No enfrentamento do problema de pesquisa, optamos por analisar um conjunto de artigos publicados em revistas brasileiras, as quais consideramos representativas da área, vinculadas à Educação em Ciências. A seleção dos artigos ocorreu em duas etapas. Na primeira, selecionamos artigos identificados, no título, resumo e/ou palavras-chave, com CTS ${ }^{4}$, nas revistas Alexandria - Revista de Educação em Ciência e Tecnologia, Ciência \& Educação, Ensaio - Pesquisa em Educação em Ciências, Experiências em Ensino de Ciências, Investigações em Ensino de Ciências e Revista Brasileira de Pesquisa em Educação em Ciências (RBPEC) $)^{5}$. Dessa etapa, resultaram 65 artigos $^{6}$. Na segunda etapa, a partir da seleção anterior, selecionamos, através da leitura de seus resumos, 24 artigos. O critério para essa seleção foi a necessidade de constituírem reflexões sobre práticas educativas efetivadas. Esse conjunto de artigos, que apresentamos no Quadro 1, compôs o corpus de análise da pesquisa que desenvolvemos.

Essas práticas ocorreram em escolas públicas (13), em instituições de formação técnica ou superior (9) e em uma escola privada (1) ${ }^{7}$. Os focos dessas práticas educativas foram o Ensino Médio (9), o Ensino Fundamental (5), cursos técnicos ou superiores (4), formação inicial de professores de Física (3), formação continuada de professores de Ciências (2) e formação continuada de professores de Química (1). As atividades versavam sobre ensino de Física (11), ensino de Química (7) e ensino de Ciências (5). Já o tempo dessas atividades apresentou um leque bastante amplo, sendo algumas de um a dois anos (4), de até um semestre (10) e até dez encontros (6).

Analisamos o material com base nos pressupostos da Análise Textual Discursiva (ATD) na qual, a partir de um conjunto de textos, produz-se um novo texto descrevendo e interpretando sentidos e significados dos textos iniciais. Na ATD (MORAES; GALIAZZI, 2011), o olhar para o material empírico, neste caso, o corpus constituído pelos 24 artigos, é balizado pelos objetivos e problema de pesquisa, bem como pelos pressupostos dos pesquisadores, estejam explicitados ou não.

\footnotetext{
${ }^{4}$ Os termos que identificamos foram: "Ciência/Tecnologia/Sociedade", "Ciência, Tecnologia e Sociedade", "Ciência-Tecnologia-Sociedade", "Ciência-Tecnologia-Sociedade-Ambiente", "CTS" ou "CTSA".

${ }^{5} \mathrm{Na}$ análise, consideramos todo o período de publicação da revista.

${ }^{6}$ A distribuição dos artigos, na primeira etapa, foi: Alexandria (9), Ciência \& Educação (20), Ensaio (9), Experiências (11), Investigações (7) e RBPEC (9).

${ }^{7}$ Em um dos artigos não está explícito o tipo de instituição de ocorrência da prática.
} 
A participação na construção do currículo: ...

Quadro 1. Corpus de análise da pesquisa.

\begin{tabular}{|c|c|c|c|c|}
\hline Revista & Autores & Ano & Volume e número & Identificação \\
\hline Alexandria & Araújo; Formenton & 2012 & 5,1 & Artigo 01 \\
\hline \multirow{9}{*}{$\begin{array}{l}\text { Ciência \& } \\
\text { Educação }\end{array}$} & Angotti; Bastos; Mion & 2001 & 7,2 & Artigo 02 \\
\hline & Andrade; Carvalho & 2002 & 8,2 & Artigo 03 \\
\hline & Samagaia; Peduzzi & 2004 & 10,2 & Artigo 04 \\
\hline & Muenchen; Auler & 2007 & 13,3 & Artigo 05 \\
\hline & Assis; Teixeira & 2009 & 15,1 & Artigo 06 \\
\hline & Machado; Pinheiro & 2010 & 16,3 & Artigo 07 \\
\hline & Firme; Amaral & 2011 & 17,2 & Artigo 08 \\
\hline & Silva; Carvalho & 2012 & 18,2 & Artigo 09 \\
\hline & Mundim; Santos & 2012 & 18,4 & Artigo 10 \\
\hline \multirow[t]{2}{*}{ Ensaio } & Barbosa; Lima; Machado & 2012 & 14,1 & Artigo 11 \\
\hline & Santos; Amaral; Maciel & 2012 & 14,1 & Artigo 12 \\
\hline \multirow{7}{*}{$\begin{array}{l}\text { Experiências } \\
\text { em Ensino } \\
\text { de Ciências }\end{array}$} & Bacussi; Ortermann & 2006 & 1,1 & Artigo 13 \\
\hline & Mion; Alves; Carvalho & 2009 & 4,2 & Artigo 14 \\
\hline & Junior; Dantas; Nobre & 2010 & 5,1 & Artigo 15 \\
\hline & Dworakowski; Marranghello; Dorneles & 2010 & 5,2 & Artigo 16 \\
\hline & Mathias; Amaral & 2010 & 5,2 & Artigo 17 \\
\hline & Santos; Amaral; Maciel & 2010 & 5,3 & Artigo 18 \\
\hline & Regis; Bello & 2011 & 6,1 & Artigo 19 \\
\hline \multirow{4}{*}{$\begin{array}{c}\text { Investigações } \\
\text { em Ensino } \\
\text { de Ciências }\end{array}$} & Sasseron; Carvalho & 2008 & 13,3 & Artigo 20 \\
\hline & Silva; Carvalho & 2009 & 14,1 & Artigo 21 \\
\hline & Marcondes et al. & 2010 & 14,2 & Artigo 22 \\
\hline & Carletto; Pinheiro & 2010 & 15,3 & Artigo 23 \\
\hline RBPEC & Muenchen; Auler & 2007 & 7,3 & Artigo 24 \\
\hline
\end{tabular}

Fonte: Elaborado pelos autores.

Para Moraes e Galiazzi (2011, p. 12), a ATD pode ser entendida como um "processo auto-organizado de construção de compreensão em que novos entendimentos emergem a partir de uma sequência recursiva de três componentes". Na primeira etapa desse processo, a desmontagem dos textos do corpus de análise, são extraídas unidades em que o analista atribuirá "sentidos e significados” (MORAES; GALIAZZI, 2011, p. 13). A segunda etapa do processo, 
o estabelecimento de relações, tendo construído os sentidos e significados das unidades textuais, constitui-se em "reunir elementos semelhantes [...] nomear e definir as categorias" (p. 23). Já na terceira etapa do processo, captação do novo emergente, as compreensões e teorizações atingidas em relação aos fenômenos estudados serão expressas e validadas.

Moraes e Galiazzi (2011) trabalham com os conceitos de significantes e significados. No entender dos autores, os significantes constituem os textos originais, ou o corpus de análise. Ainda, a ATD é uma modalidade de análise textual, de natureza qualitativa, que objetiva produzir novas compreensões sobre fenômenos e discursos investigados por meio de movimentos interpretativos de caráter hermenêutico (MORAES; GALIAZZI, 2011). Os pressupostos que balizaram o delineamento da pesquisa, bem como sua execução, foram Paulo Freire, encaminhamentos CTS e proposições do Pensamento Latino-Americano em Ciência-Tecnologia-Sociedade (PLACTS).

\section{Resultados}

Resultantes do processo de ATD, os resultados da pesquisa foram organizados em torno de quatro categorias de análise, ou seja, (i) Currículos Temáticos, (ii) Professores selecionam temas para cumprir listagens de conteúdos, (iii) Não realização da investigação dos temas e (iv) Focos de colaboração e interdisciplinaridade. As categorias (i), (ii) e (iv) foram construídas pela presença, identificação de sentidos e significados nas unidades/fragmentos do material que analisamos, em consonância com os objetivos que definimos e com nossos pressupostos teóricos, caminho caracterizado como indutivo por Moraes e Galiazzi (2011). Nesse, compreensões alcançadas partem de aspectos mais particulares, das unidades de sentido, extraídas dos artigos, em direção a aspectos mais gerais, culminando com o estabelecimento das categorias. Já a construção da categoria (iii) ocorreu pela identificação de lacunas, vazios, não contando com qualquer fragmento, qualquer núcleo de sentido extraído dos textos originais. Essa ausência se tornou presente considerando o silenciamento, nos textos analisados, sobre dimensão central em um dos referenciais que utilizamos. Ou seja, a investigação temática freireana. (FREIRE, 2005).

Independentemente do processo de construção das categorias, Moraes e Galiazzi (2011) sublinham a importância da validade e homogeneidade das mesmas, sendo aquela relacionada com a capacidade de gerar novas compreensões sobre os fenômenos e, também, que os sujeitos se identifiquem nessas categorias, enquanto esta está relacionada com a padronização quanto ao princípio conceitual de construção dessas. A construção de categorias está vinculada à necessidade de gerar conceitos abrangentes que possibilitem a compreensão dos fenômenos estudados, o que vai além da mera caracterização dos elementos reunidos em um grupo em direção ao estabelecimento de relações entre esses elementos, bem como à construção de relações entre as várias categorias emergentes da análise.

\section{Currículos temáticos}

A totalidade das práticas descritas, nos artigos que analisamos, foi estruturada em torno do que tem sido denominado temas, que é coerente com a literatura relacionada à CTS, conforme aponta Santos (2008). No entanto, o entendimento praticado pelos autores revela um amplo espectro de concepções em torno do significado de temas. Desde concepções mais 
alinhadas com temas sociais relacionados à CT, encaminhamentos mais abertos, até concepções que designam conteúdos tradicionalmente presentes, nos currículos, como temas. Organizamos essa variedade de concepções, sobre o significado de temas, em quatro conjuntos para melhor caracterizá-las e discutir seus desdobramentos.

No primeiro conjunto estão temas mais abrangentes como alimentação e vida saudável (artigo 10) ${ }^{8}$, petróleo (artigo 17), combustíveis, água e poluição (artigo 22) e o Projeto Manhattan (artigo 04). O segundo conjunto é constituído por situações-problemas relacionadas a questões ambientais como fontes de energia automotiva (artigo 01), poluentes atmosféricos (artigo 19), aquecimento global (artigo 11), buraco na camada de ozônio (artigo 06), navegação e meio ambiente (artigo 20) e temática ambiental (artigos 09 e 21).

Em ambos os conjuntos estão temas de significado social, com possibilidades de serem exploradas dimensões relativas à CT e, sobretudo, são temas mais globais não necessariamente característicos de uma região e/ou localidade. São temas com potencial para serem trabalhados em vários contextos, considerando a característica de maior globalidade. Temas com essa caracterização são defendidos por autores como Merryfield (1991 apud SANTOS; MORTIMER, 2000) em função de afetarem várias pessoas em várias partes do mundo e não apresentarem soluções apenas locais, somente podendo ser solucionados com ações mais globais, tomadas conjuntamente em vários contextos.

Outro conjunto, o terceiro, carrega a marca de conteúdos tradicionais de Física designados temas, como momento angular, interferência e difração, radiação do corpo negro e propriedades eletromagnéticas da matéria (artigo 14) e o tema energia (artigo 13). O trabalho com esses conteúdos, cuja nomenclatura resulta de um longo processo de construção, expressando alto grau de abstração, pode dificultar o diálogo, o engajamento dos estudantes, nas práticas educativas, se esses temas/conteúdos forem concebidos como ponto de partida dessas práticas. Tais temas/conteúdos, enquanto ponto de partida, podem reduzir a possibilidade de diálogo visto que, em geral, os estudantes teriam mais a falar sobre situações reais, presentes em suas vidas, cuja compreensão requer esses conteúdos.

O quarto e último conjunto é composto por trabalhos em que produtos resultantes de processos naturais e/ou industriais são considerados temas. Exemplificam esses produtos cachaça e leite (artigos 12 e 18), trabalhados como temas sociocientíficos e o descarte de pilhas (artigo 08). Próximos ao conjunto anterior, constituem, por exemplo, produtos/objetos a serem decodificados. São explorados e trabalhados conceitos científicos presentes nos mesmos. Contudo, na maioria das vezes, esses produtos e/ou aparatos são trabalhados desconsiderando-se contextos sociohistóricos em que são produzidos e utilizados.

Reconhecemos avanços nessas configurações curriculares estruturadas em torno de temas/produtos/conteúdos. No entanto, entendemos que há desafios, problematizações a serem feitas. Desafios que remetem à problematização de possíveis endossos a concepções de neutralidade da CT quando o trabalho se reduz ao uso, à decodificação desses produtos e/ou aparatos, à compreensão dos princípios científicos presentes nos mesmos. Por exemplo, temas

\footnotetext{
${ }^{8}$ Os autores associados a determinado artigo, por exemplo, “artigo 10”, foram identificados no Quadro 1. Optamos por essa sistemática para diferenciar artigos integrantes do corpus de análise dos demais utilizados ao longo do texto.
} 
ambientais, temas sociocientíficos, conteúdos tradicionais designados de temas, produtos e objetos/aparatos tecnológicos, dentre outros, podem, sendo desconsiderados os contextos sociohistóricos, atuar no sentido de ratificar compreensões de que esses são neutros, livres de valores, condicionamentos sociais, utilizáveis, sem maiores problemas, em qualquer configuração social. Em síntese, tais abordagens, muitas vezes, ignoram a pergunta: por que temos esses produtos, esses aparatos tecnológicos e não outros? Por exemplo, por que continuamos usando, majoritariamente, o motor de combustão interna se ele é, sob o ponto de vista energético, altamente ineficiente e ambientalmente insustentável? Com o encaminhamento que estamos analisando, pode ocorrer a omissão de que, no direcionamento dado ao desenvolvimento científico-tecnológico, também estão presentes valores, valores internalizados, materializados no produto científico-tecnológico. Segundo Delizoicov e Auler (2011), uma compreensão mais ampla sobre não neutralidade da CT requer a compreensão sobre essa presença de valores, compreensão que permite vislumbrar a possibilidade de outros encaminhamentos para CT.

Representantes do PLACTS, desde as décadas de 1960 e 1970, já problematizavam a suposta neutralidade de conhecimentos científico-tecnológico, produzidos em países considerados centrais, importados e disseminados na América Latina. Autores como Herrera (2000b) e Varsavsky (1969) já destacavam que processos científicos não ocorrem à margem do contexto social mais amplo, sendo que aspectos geográficos, ecológicos e econômicos, mesmo que não explicitados, influenciam esses processos. Sábato e Mackenzie (1982), em suas críticas à suposta neutralidade da CT, buscando evidenciar que ela está envolta de valores, destaca que a tecnologia, proveniente daqueles países, não é a única, não necessariamente a melhor ou a mais conveniente, da mesma forma que ela não é, por definição, a que melhor pode servir para o desenvolvimento de determinado contexto. A América Latina em seu caso.

Auler (2002), por sua vez, problematiza e tece críticas à suposta neutralidade de CT destacando, dentre outros aspectos, que o direcionamento dado ao empreendimento científicotecnológico, em outras palavras, à formulação de determinadas agendas de pesquisa, resulta de decisões associadas ao campo político. Dagnino (2008), autor que tem atualizado e reinventado o PLACTS, entende que CT não avança linear, contínua e inexoravelmente com base apenas em seus problemas internos. O autor sublinha que o desenvolvimento de CT é socialmente condicionado, apresentando a tendência de reproduzir as relações sociais dominantes e até mesmo dificultar mudanças sociais.

\section{Professores selecionam temas para cumprir listagens de conteúdos}

São inegáveis os avanços com a inclusão de temas em práticas educativas fundamentadas em CTS, estando os autores e/ou professores aproveitando espaços disponíveis para um arejamento curricular, podendo esse arejamento constituir passo inicial para reconfigurações curriculares mais abrangentes. No entanto, o cenário não é tão promissor visto que os encaminhamentos dados, à seleção dos temas, são problematizáveis a partir dos referenciais que adotamos.

Dos 24 artigos que analisamos, em 23 a definição dos temas ocorreu pelos professores e/ou pesquisadores envolvidos. Algo positivo. Nos artigos 23 e 14, além da sugestão inicial dos professores, houve a participação dos estudantes na definição dos mesmos. Votação no primeiro e sorteio no segundo. Do conjunto dos artigos, nas justificativas apresentadas, comparece, por exemplo: "cada vez mais, preocupação e prioridade de todos os governos, e que a poluição 
atmosférica tem merecido atenção" (artigo 19, p. 97), "tanto no aspecto profissional (aquisição de conhecimentos científicos e tecnológicos) quanto no aspecto humanista (formação para a cidadania)" (artigo 07, p. 530) e "impactar macro e micro escolhas referentes aos hábitos de vida de toda a sociedade" (artigo 11, p. 115).

A opção, no Artigo 10, no que se refere à seleção do tema, foi por este "permitir uma ampla discussão dos conceitos relacionados à ciência, à tecnologia e à sociedade, e por ter relação com o conteúdo que estava sendo desenvolvido na turma” (p. 793), de forma que "foi mantido o conteúdo do currículo que vinha sendo trabalhado pela professora, o qual passou a ser relacionado com as situações de vivência dos alunos" (p. 799). Excertos exemplares de que os temas são selecionados para cumprir listagens de conteúdos pré-definidas.

Apesar do tênue arejamento curricular exercitado, nas práticas educativas fundamentadas em CTS, como a inserção de temas e a possibilidade dos professores selecioná-los, algo tem permanecido pouco problematizado nessas práticas: as listagens de conteúdos que são levadas à sala de aula. Isso remete a desafios. Desafios no sentido da problematização de encaminhamentos que podem resultar em endossos a currículos tradicionais. Em linhas gerais, a utilização desses temas não tem fomentado a seleção de conteúdos outros além daqueles já presentes em configurações disciplinares tradicionais que, segundo Silva (2010), tendem a ser assumidas como neutras, científicas e desinteressadas. Silva avança destacando que as teorias tradicionais de currículo aceitam, mais facilmente, o status quo afastando-se, dessa forma, do "o quê?" ensinar e "por quê??" ensinar. Ou, por que privilegiar determinados conhecimentos em detrimento de outros?

Dessa forma, podem ser reforçadas compreensões de que CTS seria apenas uma metodologia para dinamizar a Educação em Ciências, reforçando o "como?" ensinar, sendo os temas um dispositivo para ratificar listagens pré-definidas de conteúdos disciplinares. Mesmo em configurações curriculares em que ocorrem arejamentos com a entrada desses temas, é possível perceber que as tradicionais listagens de conteúdos permanecem pouco problematizadas, atuando como condicionantes da organização espaço-temporal da escola, dado o efeito organizador que exercem.

Uma discussão sobre o histórico do surgimento das disciplinas escolares encontra-se em Goodson (2010). É possível, a partir dessa obra, avançar na compreensão sobre o condicionamento que as "listagens de conteúdos" exercem sobre a dinâmica organizativa das escolas. Por exemplo, listagens mais extensas remetem a cargas horárias maiores. Goodson (2010) também analisa a primazia dada a determinadas disciplinas em detrimento de outras. Contemporaneamente, uma suposta superioridade de algumas disciplinas é retomada, por exemplo, em artigo da revista Exame, Editora Abril, de outubro de 2013 (HORA..., 2013). No artigo "Hora da virada na educação?", é atualizada reflexão de Goodson (2010) quanto à prioridade de determinadas disciplinas no currículo. Esse artigo concebe a educação como formação de capital humano, considerado fundamental para a competição empresarial. Os pressupostos educacionais, de cunho empresarial, presentes no artigo, estão muito próximos daqueles defendidos pelo Movimento Todos pela Educação?.

${ }^{9}$ Disponível em: <http://www.todospelaeducacao.org.br/>. Acesso em: 17 mar. 2016. 
Nos artigos que analisamos, há uma segunda fala muito representativa do conjunto, em termos de listagens de conteúdos a serem cumpridas. Está presente, no Artigo 16, que os encaminhamentos CTS "constituem-se uma forma de contextualizar e problematizar o ensino das ciências" (p. 151), bem como o encaminhamento dado à prática procurando "atender os conhecimentos previstos para as diferentes séries que participaram do projeto" (p. 151) e por aprofundarem conhecimentos específicos apenas em determinadas turmas em função de "serem previstos em seu currículo, como os conceitos de dilatação térmica, em especial a dilatação dos líquidos, aplicáveis ao $2^{\circ}$ ano do EM" (p. 153).

Em parte significativa dos trabalhos analisados, os temas têm sido selecionados para dinamizar o cumprimento de listagens de conteúdos disciplinares anteriormente definidas. $\mathrm{O}$ currículo permanece pouco problematizado. Reduz-se CTS a uma nova metodologia. Há um reducionismo metodológico, aspecto também identificado por Muenchen (2006) em pesquisa sobre compreensão de professores sobre abordagem temática. Reducionismo que compromete pressupostos presentes na gênese do movimento CTS, como, por exemplo, a agenda política, materializada na concepção de novos currículos, marcados por valores que apontam horizontes distintos daqueles sinalizados pelos currículos tradicionais (AIKENHEAD, 2005). Por outro lado, temos a expectativa de que práticas, com as características citadas, se problematizadas e submetidas à crítica, podem potencializar transformações mais profundas em termos de concepções curriculares, podem sinalizar a necessidade de que outros conhecimentos, outros valores necessitam ser contemplados na educação.

\section{Não realização da investigação dos temas}

Conforme já indicamos, a construção da presente categoria teve um processo diferente das demais. Nessa, a construção ocorreu pela identificação de lacunas, "vazios", não contando com qualquer fragmento, qualquer núcleo de sentido extraído dos textos originais. Essas ausências se tornaram presentes considerando um dos referenciais que utilizamos: Freire. Para esse educador, a investigação temática, da qual resultam os temas, é algo central. Na ATD, como já destacamos, o olhar para o material empírico está relacionado às intenções, ou seja, aos objetivos da pesquisa e os pressupostos do pesquisador. Moraes e Galiazzi (2011), reiteradamente, destacam a importância dos pressupostos do pesquisador para a pesquisa, da mesma forma que consideram importantes e necessários os insights, dimensões associadas que permitiram a identificação desses vazios.

Dos 24 artigos que constituíram o corpus da pesquisa, em 12 há referências ao trabalho de Paulo Freire, aspecto que corrobora resultado encontrado por Strieder (2012) sobre a aproximação Freire-CTS no contexto brasileiro. Ainda, no corpus que analisamos, embora com diferentes níveis de profundidade, em 23 dos artigos, praticamente na totalidade, existem preocupações, no campo do discurso, de que CTS incida nos currículos, que haja uma repercussão dos estudos CTS nos currículos escolares, nos currículos de formação de professores. No entanto, nesses 24 artigos analisados, não comparece, ou não foi explicitado, qualquer menção à construção do currículo a partir da investigação temática, possivelmente um dos principais contributos da obra do autor para a educação. Não foi possível, nessa categoria, trazer fragmentos dos artigos analisados, considerando que essa surge, exatamente, do silêncio sobre a investigação temática. 
Apesar da preocupação discursiva dos autores, a concepção e a construção de novos currículos foi muito pouco exercitada no material que analisamos. Novamente, comparece um indicativo de que a participação dos professores tem ocorrido após a definição de listagens de conteúdos. Listagens cristalizadas e repetidas ano após ano. Listagens definidoras da dinâmica organizacional do espaço-tempo da escola. Por exemplo, naquelas disciplinas em que as listagens são extensas, há uma carga horária maior.

O encaminhamento defendido e praticado por Freire, no conjunto de sua obra, é pautado por temas, defendendo a utilização de temas reais/locais, via investigação temática, nos currículos escolares. Mesmo que Freire não tenha se preocupado em desenvolver uma teoria de currículo, mediante a concepção de temas geradores e sua crítica ao que denominou de educação bancária, Freire (2005) avança em relação a duas questões centrais sobre teorias de currículo: "o quê?" e "por quê?" ensinar.

A investigação temática, em Freire (2005), tem como pressuposto a participação da comunidade escolar, juntamente com equipe interdisciplinar, para identificar temas, problemas locais nos quais contradições sociais mais amplas estejam manifestas. Temas que sinalizarão "novas listagens de conteúdos" a serem trabalhadas. A matriz educacional, do conjunto da obra freireana, está apoiada em uma concepção de interação dialógica entre os envolvidos, diálogo que Freire $(2005,2006)$ considera ter início justamente na busca de temas com as características acima. Temas que constituirão eixos estruturantes do currículo, temas que guiarão a seleção de conhecimentos, também os disciplinares, a serem trabalhados em sala de aula.

Após a definição do tema, ocorre o que o autor denominou redução temática, a qual consiste na seleção de conhecimentos necessários à compreensão e possível enfrentamento do tema, bem como sua estruturação didático-pedagógica. Na concepção freireana, esses conhecimentos iluminam, ajudam a compreender e enfrentar o tema selecionado. No mesmo processo, em articulação com a equipe interdisciplinar, a comunidade local tem as primeiras possibilidades de dizer sua palavra, algo central ao se propor a superação da cultura de silêncio em direção a uma cultura de participação.

Entendemos que a articulação Freire-CTS pode potencializar, de forma mais consistente, processos educativos em relação àqueles em que esses dois referenciais são trabalhados isoladamente. Pressupostos freireanos têm, dentre outros, dois contributos fundamentais, ausentes ou frágeis no campo CTS: a investigação temática e a explicitação de objetivos educacionais, algo um tanto nebuloso, no campo CTS, segundo Strieder (2012). CTS, dependendo do encaminhamento selecionado, considerando seu espectro polissêmico, pode contribuir com aportes no campo da reflexão epistemológica e sociológica da CT, algo frágil em Freire.

A concepção curricular experenciada por Freire, via investigação temática, faz com que o fazer educacional incida sobre "o quê?" ensinar e o "por quê?" ensinar. Esse encaminhamento rompe profundamente com encaminhamentos tradicionais do currículo e contribui para problematizar e superar currículos cristalizados. Após décadas de trabalhos balizados por pressupostos freireanos, há um conjunto bastante consistente de sinalizações apontando o fato de que, currículos fundamentados no processo de investigação/redução temática, potencializam o que esse autor denominou curiosidade epistemológica. Ou seja, o engajamento dos estudantes no ato de aprender, uma predisposição favorável diante do que é estudado. Possivelmente, a ausência dessa curiosidade contribui para compreender a evasão, a repetência, a falta de significado que o conjunto dos estudantes brasileiros atribui à escola, ao currículo (FERRÃO; AULER, 2012). 


\section{Focos de colaboração e interdisciplinaridade}

Severino (1988 apud SAMPAIO; QUADRADO; PIMENTEL, 1994) disse que a interdisciplinaridade seria algo necessário, embora ainda não vivida e explicitada, uma experiência pressentida e desejada. Já Japiassu (1976) entendia que a interdisciplinaridade estava longe de ser algo evidente. Auler (2007), em análise dos pressupostos freireanos e encaminhamentos CTS, destaca que, em ambos, a postulação da categoria interdisciplinaridade está presente. Dos artigos que analisamos, identificamos um conjunto que buscou superar a fragmentação disciplinar, o desenvolvimento de um trabalho coletivo, bem como tênues modificações no campo curricular.

Exemplifica esse conjunto o Artigo 23, no qual houve um "planejamento e cooperação entre disciplinas das seguintes áreas: Biologia, Física, Química, Matemática, Português, História e Filosofia" (p. 508), principalmente em função de "uma manhã semanal que a instituição determinava no horário de todos os professores para discussão, estudo e planejamento" (p. 520). Esse constitui encaminhamento que se aproxima da abordagem temática (DELIZOICOV, ANGOT'TI e PERNAMBUCO, 2007; FREIRE, 2005), de caráter interdisciplinar, presente nos referenciais que temos assumido na pesquisa e que explicitamos anteriormente.

Delizoicov e Zanetic (2002), ancorados em pressupostos freireanos, consideram que a interdisciplinaridade parte do pressuposto de que várias ciências podem contribuir para o entendimento de temas que orientam o trabalho escolar. Segundo eles, pode ser considerada como uma lente que decompõe o tema em diversas disciplinas, matemática, história, sociologia, geografia, línguas, etc., permitindo evidenciar aspectos fragmentados do tema em questão. As disciplinas decompostas, ao serem reintegradas, tendo como pano de fundo uma maior bagagem cultural, por meio de seu estudo sistemático, permitem uma melhor e mais abrangente compreensão do tema em questão. Severino (1988 apud SAMPAIO; QUADRADO; PIMENTEL, 1994) ajuda a compreender o entendimento de Delizoicov e Zanetic (2002). Para ele, uma compreensão de maior totalidade, que pode ser relacionada a um tema, não ocorre de forma fragmentada, seccionada, ela só pode ocorrer em um processo colaborativo e solidário entre diversas disciplinas.

Destacamos que temas mais recentes como mudanças climáticas, energias renováveis, sustentabilidade, consumismo, mobilidade urbana, etc., são complexos e, em função de sua natureza, não podem ser compreendidos/enfrentados apenas por um campo disciplinar. Nesse ponto, é fundamental a contribuição de Dagnino (2010) quanto à abordagem desse tipo de temas. Embora não esteja discorrendo sobre currículo, mas sobre o enfrentamento que a universidade dá (ou não dá) aos temas sociais, considera a abordagem equivocada, considerando a organização majoritária das instituições de ensino superior no Brasil. Para Dagnino (2010), constitui um equívoco a tentativa de enfrentar um tema sob o ponto de vista disciplinar, ou departamental, como ocorre nas universidades brasileiras. $\mathrm{O}$ autor evidencia que nenhum tema social é etiquetado como pertencente à "sociologia", "economia", "antropologia", etc., mas são interdisciplinares, requerem a abordagem sob vários focos disciplinares, algo semelhante às "luzes decompostas" de Delizoicov e Zanetic (2002).

A partir de um tema real, decorrente da investigação temática freireana, que conteúdos disciplinares contribuem para o entendimento deste? Respostas a essa pergunta podem sinalizar caminhos para novos currículos. Encaminhamento que não negligencia os campos disciplinares, mas enfatiza a necessidade de trabalhos coletivos/interdisciplinares entre as mais diversas áreas do conhecimento. Ainda, encaminhamento que pode contribuir para a constituição de 
concepções de mundo ampliadas por parte dos professores, considerando que seus processos formativos, em linhas gerais, ocorreram em um único campo disciplinar.

Outra prática educativa, também com elementos promissores, foi a analisada no Artigo 16. Nessa, sobre a construção de um aquecedor solar, além de professores de Física, houve a participação de professores de Sociologia e Química, os quais se engajaram no projeto. Os autores sublinham que a "professora de sociologia pôde trabalhar os aspectos sociais envolvidos na coleta seletiva do lixo e das famílias que tiram seu sustento do reaproveitamento do lixo seco reciclável também a importância desse trabalho para a preservação ambiental” (p. 155), enquanto o "professor de química fez o balanço de massa com seus alunos, comparando o consumo de carvão mineral necessário para gerar energia elétrica na usina de Candiota-RS” (p. 155).

A partir da iniciativa de professores de Física, os de Química e Sociologia se engajaram no projeto, trabalhando segundo suas possibilidades. Destacando o potencial desse encaminhamento, problematizamos alguns aspectos na perspectiva de sua potencialização. A seleção do tema, mediante o qual selecionaram-se conhecimentos disciplinares, foi feita pelos professores de física. Mesmo o tema sendo bastante relevante para a região, em função de sua matriz energética, a atuação dos demais professores está circunscrita à delimitação feita sob critérios mais próximos da Física. Professores de outras disciplinas, ou um coletivo multidisciplinar, teriam chegado ao mesmo tema?

Em dois outros trabalhos, Artigos 09 e 21, trabalhando temas ambientais e controversos, com licenciandos de Física, analisaram obstáculos a serem enfrentados na abordagem desses temas. No processo reflexivo empreendido, com esses licenciandos, comparecem, ainda que de forma bastante inicial, discussões sobre interdisciplinaridade.

O Artigo 03 descreve e analisa a elaboração da temática Proálcool, desenvolvida em turma de estudantes da sexta série, em uma região de grandes canaviais e indústrias de processamento. Efetivamente, a proposta contempla vários campos de conhecimento, inclusive muitos desses não presentes nos currículos convencionais. Essa constitui uma das dificuldades apontadas pelos autores:

A outra grande dificuldade é a de lidar, em sala de aula, com um tema que envolve, além de conhecimentos biológicos mais objetivos e já tradicionalmente trabalhados nas aulas de Ciências, outros pertencentes a áreas não muito exploradas em atividades de ensino de Ciências Naturais, como, por exemplo, conhecimentos de biotecnologia. Uma outra dimensão do trabalho com a qual o professor não tem muita familiaridade é a discussão de temas envolvendo valores, interesses de grupos sociais específicos e um sistema de crenças que está em jogo (Artigo 03, p. 184).

Esse último trabalho revela um dilema enfrentado em práticas interdisciplinares. Como superar a solidão de professores que buscam práticas com essa característica, se o currículo é disciplinar e é quem organiza e distribui professores, estudantes e disciplinas em espaços-tempos rigidamente definidos? Neste trabalho, há uma tentação, saudável e corajosa, de poucos professores, em se aventurar em campos de conhecimento não presentes em sua formação inicial. Contudo, qual o nível de profundidade com que esses campos poderão ser trabalhados? Por um lado, essas "aventuras interdisciplinares" permitirão a ampliação dos horizontes culturais 
dos envolvidos. De outro, não parece promissor reivindicar que um professor domine todos os campos de conhecimentos, o que seria o professor "polivalente" problematizado por Delizoicov e Zanetic (2002). Novamente, a formação de coletivos multidisciplinares, mediados por um tema, conforme estamos analisando ao longo deste artigo, parece constituir caminho pertinente.

As problematizações que fizemos, nas práticas interdisciplinares anteriores, buscam, de um lado, destacar o esforço, dentro da atual organização espaço-temporal da escola, feito por seus protagonistas. Seus trabalhos são portadores e sinalizadores de novos horizontes. Talvez representem o possível dentro de contextos adversos. De outro, se não tivermos uma compreensão dos limites colocados pela organização espaço-temporal da escola, podemos nos iludir reduzindo o não avanço, de práticas mais interdisciplinares, à formação deficiente dos professores, a uma suposta falta de vontade dos mesmos. Uma responsabilização, única, do sujeito professor. Essas problematizações querem sinalizar a necessidade de rupturas na organização espaço-temporal da escola, sem as quais, possivelmente, ficaremos, por um longo tempo, reféns das sempre "práticas possíveis", pontuais, não amplificadas.

\section{Considerações finais}

Como tem sido a definição e estruturação de currículos em práticas educativas realizadas no campo CTS? As respostas que encontramos para essa pergunta foram sintetizadas em quatro categorias: (i) Currículos temáticos, (ii) Professores selecionam temas para cumprir listagens de conteúdos, (iii) Não realização da investigação dos temas e (iv) Focos de colaboração e interdisciplinaridade. Destacamos que não pode ser ignorado o fato de que a análise abarcou parte limitada da produção CTS presente no contexto brasileiro. Vinculado a essas categorias, identificamos limitações que sinalizam desafios para a Educação em Ciências, dentre as quais destacamos: possível esvaziamento de pressupostos freireanos em CTS, indícios de um reducionismo metodológico (reduz o papel do professor ao como ensinar) e o consumismo não problematizado.

O tema energia está bastante presente nos artigos que analisamos. No entanto, não comparecem reflexões mais aprofundadas quanto ao consumismo, quanto à lógica da obsolescência programada, a qual implica degradação de energia, aspecto intrinsecamente ligado à degradação socioambiental. Em outras palavras, o valor supremo do atual modelo de organização social, o capitalismo, dinamizador de um modelo socioeconômico possivelmente causador de mudanças socioambientais nada animadoras, permanece oculto, ignorado, não problematizado. Um exemplo é o Artigo 16 que, mesmo avançando para além da fragmentação curricular, conforme destacamos, silencia sobre a lógica consumista dando visibilidade ao pós-produção, ao pós-consumo: coleta seletiva de lixo, seu reaproveitamento. Se o trabalho desenvolvido, na escola, focalizar apenas reciclagem de lixo, a matriz econômico-produtiva, altamente poluidora e geradora de resíduos, visíveis e invisíveis, permanecerá longe do alcance da problematização, de uma reflexão crítica.

Parte das repercussões educacionais de CTS, no contexto brasileiro, têm ficado restritas aos usos de CT, à análise de impactos considerados positivos e negativos, no sentido de potencializar os primeiros e reduzir os segundos. Isso pode significar um endosso à atual agenda de pesquisa, no campo científico-tecnológico, notadamente marcada pelo consumismo, pela 
inovação, pela competitividade, pela obsolescência programada, estando essa agenda capturada pelas transnacionais. Nesse sentido, a apropriação, no campo educacional, de elementos do PLACTS, discutidos ao longo do texto, pode potencializar um horizonte ampliado de participação. Participação que vá além de uma avaliação dos impactos da CT na sociedade. Participação que incida, também, na agenda de pesquisa, na formulação de políticas públicas para a CT. Uma participação que não se limite ao pós-produção, ao pós-consumo. Uma participação que problematize, por exemplo, se é razoável a continuidade do atual modelo de transporte de pessoas e cargas, pautado, majoritariamente, no motor de combustão interna. Isso se os alertas sobre mudanças climáticas nos dizem algo.

$\mathrm{Na}$ pesquisa, de forma geral, têm sido os professores os únicos responsáveis pela seleção dos temas de estudo, o que representa um avanço importante. Significa que eles estão se apropriando das pequenas margens de manobra existentes. No entanto, possivelmente condicionados por essa pequena margem, essa participação ocorre após a definição dos conhecimentos que serão levados às salas de aula, considerados imprescindíveis, materializados nas tradicionais listagens de conteúdos disciplinares. Listagens que têm, historicamente, conforme destacado ao longo do texto, assumido uma centralidade na dinâmica organizativa do espaço-tempo da escola.

Se, de um lado, a inserção de temas, escolhidos pelos professores, pode significar um tênue arejamento na organização desse espaço-tempo, de outro, ao inserir temas para ilustrar os conteúdos de suas disciplinas, esses professores tendem a selecionar temas mais simples, menos complexos, de forma que possam ser enfrentados apenas por uma ou poucas disciplinas. Ou, ainda, compreensíveis com aqueles conhecimentos já cristalizados nos currículos. Por questão de segurança, o que é compreensível, determinado tema passa a ser analisado apenas sob a ótica de um campo de conhecimento, seja da Química, da Matemática, da Física ou da Biologia. Mas essas disciplinas, em geral, com exceção de algumas práticas promissoras, sinalizadas ao longo do texto, pouco têm sido articuladas na abordagem de tais temas. Ainda, conhecimentos que extrapolem as chamadas ciências naturais, em geral, são apenas sinalizados, sem aprofundamento. Por exemplo, conhecimentos ligados à economia, à política ou aos valores subjacentes a todo o processo. Essa primazia dada, ao campo das ciências naturais, pode contribuir, segundo Auler (2011), para o reforço de modelos decisórios tecnocráticos.

Da mesma forma que Strieder (2012), identificamos que Freire é bastante citado nos artigos analisados, tanto por aproximações entre objetivos CTS e pressupostos freireanos, quanto pela filiação teórica assumida pelos autores. Porém, como apontamos, a essência do trabalho de Freire tem sido ignorada ou não explicitada nas práticas analisadas. Ou seja, a investigação temática. Não postulamos um referencial único na educação. Também não estamos defendendo que apenas práticas educativas que tenham como ponto de partida a investigação temática sejam pertinentes. Contudo, é necessário que haja coerência com os referenciais assumidos, o que parece frágil em parte dos artigos analisados, sobretudo nos que aproximam CTS e Freire, visto que ignoram o que é essencial na obra do educador. Parece que, em alguns casos, Freire é citado para camuflar práticas curriculares cristalizadas.

Em síntese, da mesma forma que entendemos que o PLACTS pode contribuir para uma compreensão e uma participação ampliada em processos decisórios envolvendo CT, também reiteramos o papel potencializador do referencial freireano para que professores e comunidade escolar tenham uma participação ampliada na constituição curricular. Uma participação no que é essencial: “o quê?” ensinar e o "por quê?” ensinar. Entendemos que a investigação temática 
freireana tem potencial para a identificação de demandas da comunidade, que podem subsidiar tanto a construção de currículos, quanto a elaboração de novas agendas de pesquisa, de políticas públicas para o campo científico-tecnológico, conforme reivindicado pelo PLACTS. Processo que, conforme defendemos ao longo do artigo, pode contribuir para a constituição de uma cultura ampliada de participação.

Uma sinalização final, que nos parece fundamental, consiste em destacar a necessidade de um profundo repensar do processo de formação de professores. O campo curricular continuará silenciado, particularmente na Educação Básica, se a discussão sobre ele continuar ausente da formação do sujeito com um papel central no processo, o(a) professor(a). Em outras palavras, o arejamento curricular deverá chegar aos cursos de licenciatura e aos cursos de formação continuada de professores(as). Se a opção for ir para além da concepção curricular tradicional. Opção, por exemplo, presente em práxis vivenciadas e analisadas por Roso et. al (2015) e Strieder, Watanabe-Caramello e Gehlen (2012).

\section{Agradecimentos}

Os autores agradecem o apoio da Coordenação de Aperfeiçoamento de Pessoal de Nível Superior (Capes) e do Conselho Nacional de Desenvolvimento Científico e Tecnológico (CNPq).

\section{Referências}

AIKENHEAD, G. Educación ciencia-tecnología-sociedad (CTS): una buena idea como quiera que se le llame. Educación Química, México, v. 16, n. 2, p. 304-15, 2005.

AULER, D. Enfoque ciência-tecnologia-sociedade: pressupostos para o contexto brasileiro.

Ciência \& Ensino, Campinas, v.1, n. especial, p. 1-20, 2007.

Interações entre ciência-tecnologia-sociedade no contexto da formação de professores de ciências. 2002. Tese (Doutorado em Educação) - Centro de Educação, Universidade Federal de Santa Catarina, Florianópolis, 2002.

. Novos caminhos para a educação CTS: ampliando a participação. In: SANTOS, W. L. P.; AULER, D. (Org.). CTS e educação científica: desafios, tendências e resultados de pesquisas. Brasíli: Universidade de Brasília, 2011. p. 73-98.

AULER, D.; DELIZOICOV, D. Ciência-tecnologia-sociedade: relações estabelecidas por professores de ciências. Revista Electrónica de Enseñanza de las Ciências, Vigo, v. 5, n. 2, p. 337-355, 2006.

DAGNINO, R. P. Uma estória sobre ciência e tecnologia, ou começando pela extensão universitária. In: (Org.). Estudos sociais da ciência e tecnologia \& política de ciência e tecnologia: alternativas para uma nova América Latina. Campina Grande: EDUEPB, 2010. p. 281-312. 
A participação na construção do currículo: ...

DAGNINO, R. P. As trajetórias dos estudos sobre ciência, tecnologia e sociedade e da política científica e tecnológica na Ibero-América. Alexandria: revista de educação em ciência e tecnologia, Florianópolis, v. 1, n. 2, p. 3-36, 2008.

DELIZOICOV, D. Pesquisa em ensino de ciências como ciências humanas aplicadas. In: NARDI, R. (Org.). A pesquisa em ensino de ciências no Brasil: alguns recortes. São Paulo: Escrituras, 2007. p. 413-449.

DELIZOICOV, D.; ANGOTTTI, J. A. P.; PERNAMBUCO, M. M. C. Ensino de ciências: fundamentos e métodos. 2. ed. São Paulo: Cortez, 2007.

DELIZOICOV, D.; AULER, D. Ciência, tecnologia e formação social do espaço: questões sobre a não-neutralidade. Alexandria: revista de educação em ciência e tecnologia, Florianópoli, v. 4, n. 2, p. 247-73, 2011.

DELIZOICOV, D.; ZANETIC, J. A proposta de interdisciplinaridade e o seu impacto no ensino municipal de $1^{\circ}$ grau. In: PONTUSCHKA, N. Ousadia no diálogo: interdisciplinaridade na escola pública. 4. ed. São Paulo: Loyola, 2002. p. 9-15.

FERRÃO, L. V.; AULER, D. Os estudantes do arquivo morto. Revista Educação, Santa Maria, v. 37, n. 1, p. 1-14, 2012.

FREIRE, P. Extensão ou comunicação? 13. ed. Rio de Janeiro: Paz e Terra, 2006.

Pedagogia do oprimido. Rio de Janeiro: Paz e Terra, 2005.

GARCÍA, M. I. G.; CEREZO, J. A. L.; LÓPEZ, J. L. L. Ciencia, tecnología y sociedad: una introducción al estudio social de la ciencia y la tecnología. Madrid: Tecnos, 1996.

GOODSON, I. F. Currículo: teoria e história. 11. ed. Petrópolis: Vozes, 2010.

HERRERA, A. O. A responsabilidade social do cientista. In: DAGNINO, R. (Org.). Amilcar Herrera: um intelectual latino-americano. Campinas: UNICAMP, 2000a. p. 90-91.

- Transferência de tecnologia, uma atividade antiga e problema novo. In: DAGNINO,

R. P. (Org.). Amilcar Herrera: um intelectual latino-americano. Campinas: UNICAMP, 2000b. p. 34-37.

HORA da virada na educação? Exame, São Paulo, 30 out. 2013.

JAPIASSU, H. O mito da neutralidade científica. Rio de Janeiro: Imago, 1976.

LEMGRUBER, M. S. Um panorama da educação em ciências. Educação em Foco, Juiz de Fora, v. 5, n. 1, p. 13-28, 2000.

MONTEIRO, R. S. Entre monoculturas e ecologias: as percepções do público dos museus de ciência e técnica sobre as relações ciência, tecnologia, sociedade e ambiente (CTSA).

2011. Dissertação (Mestrado em Educação) - Universidade Federal do Rio de Janeiro, Rio de Janeiro, 2011.

MORAES, R.; GALIAZZI, M. C. Análise textual discursiva. 2. ed. Ijuí: Editora UNIJUÍ, 2011. 
MUENCHEN, C. Configurações curriculares mediante o enfoque CTS: desafios a serem enfrentados na EJA. 2006. Dissertação (Mestrado em Educação) - Universidade Federal de Santa Maria, Santa Maria, 2006.

NASCIMENTO, T. G.; VON LINSINGEN, I. Articulações entre o enfoque CTS e a pedagogia de Paulo Freire como base para o ensino de ciências. Convergencia, Toluca, v. 13, n. 42, p. 95-116, 2006.

ROSA S. E. Não neutralidade da ciência-tecnologia: problematizando silenciamentos em práticas educativas relacionadas a CTS. 2014. Dissertação (Mestrado em Educação) Universidade Federal de Santa Maria, Santa Maria, 2014.

ROSO, C. C. A participação na construção do currículo: práticas educativas vinculadas ao movimento CTS. 2014. Dissertação (Mestrado em Educação) - Centro de Educação, Universidade Federal de Santa Maria, Santa Maria, 2014.

ROSO, C. C.; DALMOLIN, A. M. T.; AULER, D. Práticas educativas balizadas por Freire e CTS. In: ENCONTRO NACIONAL DE PESQUISA EM EDUCAÇÃO EM CIÊNCIAS, 8., 2011, Campina. Anais... Rio de Janeiro: ABRAPEC, 2011. Disponível em: < http://www. nutes.ufrj.br/abrapec/viiienpec/resumos/R0060-1.pdf>. Acesso em: 17 mar. 2016.

ROSO, C. C. et al. Currículo temático fundamentado em Freire-CTS: engajamento de professores de física em formação inicial. Ensaio: pesquisa em educação em ciências, Belo Horizonte, v. 17, n. 2, p. 372-389, 2015.

SÁBATO, J.; BOTANA, N. La ciencia y la tecnología en el desarrollo futuro de América Latina. In: HERRERA, A. O. America Latina: ciencia y tecnologia en el desarrollo de la sociedad. Santiago: Editorial Universitaria, 1970. p. 1-11.

SÁBATO, J. A.; MACKENZIE, M. La producción de tecnología: autónoma o transnacional. México: Nueva Imagen, 1982.

SAMPAIO, M. M. F.; QUADRADO, A. D.; PIMENTEL, Z. P. Interdisciplinaridade no município de São Paulo. Brasília: INEP, 1994.

SANTOS, W. L. P. Educação científica humanística em uma perspectiva Freireana: resgatando a função do ensino de CTS. Alexandria: revista de educação em ciência e tecnologia, Florianópolis, v. 1, n. 1, p. 109-131, 2008.

SANTOS, W. L. P.; MORTIMER, E. F. Uma análise de pressupostos teóricos da abordagem C-T-S (ciência -tecnologia-sociedade) no contexto da educação brasileira. Ensaio: pesquisa em educação em ciências, Belo Horizonte, v. 2, n. 2, p. 1-23, 2000.

SILVA, T. T. Documentos de identidade: uma introdução às teorias do currículo. 3. ed. Belo Horizonte: Autêntica, 2010.

STRIEDER, R. B. Abordagem CTS e ensino médio: espaços de articulação. 2008. Dissertação (Mestrado em Ensino de Ciências) - Universidade de São Paulo, São Paulo, 2008. 
STRIEDER, R. B. Abordagens CTS na educação científica no Brasil: sentidos e perspectivas. 2012. Tese (Doutorado em Ensino de Ciências) - Universidade de São Paulo, São Paulo, 2012.

STRIEDER, R. B.; WATANABE-CARAMELLO, G.; GEHLEN, S. T. Abordagem de temas no ensino médio: compreensões de professores de física. Ensaio: pesquisa em educação em ciências, Belo Horizonte, v. 14, n. 2, p. 153-169, 2012.

VARSAVSKY, O. Ciencia, política y cientificismo. 6. ed. Buenos Aires: Centro Editor de América Latina, 1969.

Por uma política científica nacional. Rio de Janeiro: Paz e Terra, 1976.

Artigo recebido em 02/12/2014. Aceito em 16/12/2015.

Endereço para contato: Universidade Federal de Santa Catarina (UFSC), Centro de Ciências Físicas e Matemáticas, Programa de Pós-Graduação em Educação Científica e Tecnológica, Rua Eng. Agronômico Andrei Cristian Ferreira, s/n, CEP 88040-900, Florianópolis, SC, Brasil. 